\title{
Evaluation of Endectocides and Conventional Acaricides in the Control of the Boophilus microplus on Field-Kept Dairy Cattle in the State of Pernambuco-Brazil
}

\author{
Vania Lucia Assis Santana ${ }^{1}$, Maria Aparecida Da Gloria Faustino ${ }^{2}$, Erika Korinfsky Vanderley ${ }^{2}$, \\ Marilene Maria Lima ${ }^{3}$, Leucio Camara Alves ${ }^{2}$ \\ ${ }^{1}$ Ministry of Agriculture, Livestock and Food Supply, National Laboratory of Animal and Plant, \\ Rua Dom Manoel de Medeiros, Recife, Brazil \\ ${ }^{2}$ Department of Veterinary Medicine, Federal Rural University of Pernambuco, Recife, Brazil \\ ${ }^{3}$ Academic Unit of Serra Talhada, Federal Rural University of Pernambuco, Serra Talhada, Brazil \\ Email: vania.lucia@agricultura.gov.br
}

Received July 2, 2012; revised July 30, 2012; accepted August 10, 2012

\begin{abstract}
The aim of the present study was to evaluate different acaricide treatments for the control of Boophilus microplus on field-kept dairy cattle in the state of Pernambuco, Brazil. The first phase of the experiment consisted of collecting the ingurgitated female Boophilus microplus directly from the hosts for attainment of larvae. After the attainment of larvae, the artificial infestation procedure began on the cattle, with larvae ages ranging from 7 to 14 days. On Day 0 , animals were separated into 12 groups to receive the corresponding treatment: Abamectin; Ivermectin; Ivermectin LA; Amitraz; Amitraz + Ivermectin; Amitraz + Ivermectin LA; Amitraz + Abamectin; Association (Cypermethrin + Chlorpyrifos + Citronella); Association + Ivermectin; Association + Ivermectin LA; Association + Abamectin; and Control. Subsequent evaluations were made on post-treatment days $+7,+14,+21,+28,+35,+42,+49,+56$ and +63 . Analyzing the post-treatment effectiveness per day, indices revealed considerable variation ranging from $0 \%$ to $96.63 \%$. Such indices demonstrate the significant reduction in the number of ticks on the animals in some groups, especially in the Abamectin group. The analysis of the results demonstrates that the use of different avermectines can assist in the development of Boophilus microplus control programs, thereby reducing the number of acaricide applications and production costs related to ticks.
\end{abstract}

Keywords: Boophilus microplus; Tick; Carrapaticide; Efficiency; Resistance

\section{Introduction}

The control of the tick Boophilus microplus includes the systematic use of acaricide products on cattle, which has had diverse consequences for the animal as well as for livestock farmers and the tick itself. Jonsson [1] states that even when losses are controlled, there are costs involving chemicals, labor and equipment as well as production losses associated to the treatment and the cost of restricting access of the animals to determined areas. While the effective control of the tick seems to be a socioeconomic necessity for farmers, the environmental effects generated by such products are often not considered and such effects on non-targeted organisms vary from product to product [2].

Along with the problem of resistance, other factors limit the effectiveness of acaricides, such as the method of preparation and application of the product as well as the time and frequency of treatment. Solution preparation can be considered one of the most important phases in the use of products aimed at killing ticks [1,3].

The use of endectocides thus becomes in an additional alternative for controlling resistant ticks along with formularizations of prolonged action, which have recently been launched in the market [4]. The aim of the present work was to evaluate different acaricide treatments for the control of Boophilus microplus on field-kept dairy cattle in the state of Pernambuco, Brazil.

\section{Materials and Methods}

The present study was carried out on the farm of the Experimental Station of the Agriculture and Livestock Research Institute, located in the city of São Bento of Una, Pernambuco, using Holstein cattle. Female cattle in the reproductive phase were used, weighing an average of 600 $\mathrm{kg}$ and totaling 66 animals. The animals fed on grass (grass native and Brachiaria), also receiving a mineral sup- 
plement twice a day, mesquite and the fodder plant Pennisetum purpureum with palm leaves and sugarcane leaves.

The first phase of the experiment consisted of collecting the ingurgitated female Boophilus microplus directly from the hosts for attainment of larvae. Specimens were sent to the Laboratory of Parasitic Diseases in Domesticated Animals of the Department of Medicine Veterinary at the UFRPE, where they were cleaned, placed in Petri dishes and kept at room temperature $\left(25^{\circ} \mathrm{C}\right.$ to $31^{\circ} \mathrm{C}$; relative humidity above $70 \%$ ) in the laboratory. After the attainment of larvae, the artificial infestation procedure began on the cattle, with larvae ages ranging from 7 to 14 days. For such, the animals were duly contained and the larvae deposited along the dorsal line, placing about 2500 larvae per animal 21 days prior to treatment (Day -21); the procedure was repeated on Day -14 and Day -7 .

On Day 0 (day of treatment), the animals were separated into groups, each composed of 04 (four) to 08 (eight) animals under the same sanitary and feeding conditions, selected non-probabilistically by convenience for the formation of the following experimental groups:

Group I: Abamectin ${ }^{1}$ (08 animals)

Group II: Ivermectin ${ }^{1}$ (08 animals)

Group III: Ivermectin LA ${ }^{1}$ (08 animals)

Group IV: Amitraz (05 animals)

Group V: Amitraz + Ivermectin (06 animals)

Group VI: Amitraz + Ivermectin LA (04 animals)

Group VII: Amitraz + Abamectin (05 animals)

Group VIII: Association ${ }^{2}$ (04 animals)

Group IX: Association + Ivermectin (04 animals)

Group X: Association + Ivermectin LA (04 animals)

Group XI: Association + Abamectin (05 animals)

Group XII: Control (04 animals)

The initial degree of infestation of the animals was measured, counting the number of females with a diameter $\geq 4 \mathrm{~mm}$ [5] on the left side of the animal and recording the results.

The experimental groups then received the corresponding treatment. Products were applied following the manufacturers' instructions. For the control group, the only procedure carried out was the tick count. Subsequent evaluations were made on post-treatment Days $+7,+14,+21$, $+28,+35,+42,+49,+56$ and +63 .

The final effectiveness of the treatments was calculated by post-treatment Day 56, using the following equation [6]:

$$
E=\frac{a-b}{a} \times 100
$$

where

$E=$ Therapeutic effectiveness

$a=$ Average number of ticks in the group control

$b=$ Average number of ticks in the treated group

For the determination of statistical differences between treatment groups, the F test (ANOVA) was used and paired comparisons were evaluated using the Tukey test. The level of statistical significance was set at 5.0\%. The Statistical Package for Social Sciences (version 11) was used for the calculations.

\section{Results and Discussion}

On Day 0, high infestation for all tick instars was evidenced, with a predominance of females. The arithmetic average of the number of ticks ranged from 136 to 370.75 , oscillating in all groups treated in the period from 7 to 63 days following treatment. Table 1 displays the average number and standard deviation of the number of ticks per day analyzed. With the exception of the groups treated with the Association and the group control, there was a reduction in counts from Day 0 to Day +7 .

On Day +7 , the lowest averages of ticks occurred among the Amitraz + Abamectin (33.00), Abamectin (30.13), Amitraz + Ivermectin (41.33) and Amitraz + Ivermectin LA (46.25) groups. The Tukey test for paired comparisons revealed significant differences between treatments, except on Days 0 and 63. The analysis of the effectiveness of the groups per post-treatment day (Table 2) revealed that indices obtained a great variation $(0 \%$ $96.63 \%$ ), reaching considerable values of effectiveness. Such indices revealed the reduction in the number of ticks on the animals. However, the effectiveness of the treatments can better be evaluated by analyzing the animals individually.

The individual study of the animals revealed differences in the behavior of the infestations by the tick; some animals exhibited more or less parasites than others in the same treatment group, demonstrating the resistance of the host to tick attacks, consisting of the optimum method of non-chemical control of the tick, as cited by Jonsson et al. [7]. Animals with a predominantly white hide exhibited greater resistance to ticks that those with a predominance of black; this fact was previously reported by Oliveira and Alencar [8] and Teodoro et al. [9]. The control group exhibited increasing levels of tick infestation and was submitted to treatment on Day +56 . Lacking a control group thereafter, the effectiveness of the other groups was not calculated on Day +63 .

Abamectin presented good levels of effectiveness on Days $+7,+14$ and +21 , with average indices of $88.78 \%$, $79 \%$ and $84.01 \%$, respectively, which were higher than the indices of standard ivermectin and ivermectin LA. Constancy in the effectiveness of treatments on the animals in the abamectin group is evident and the animals from this group were the only ones that did not undergo a repetition of the treatment on Day +28 . When abamectin was associated jointly with amitraz, there was considerable effectiveness on Days $+7,+14$ and +21 , but tick counts were higher on Day +28 , which led to a repetition of treatment. The administration of abamectin together 
Table 1. Average and standard deviation of number of Boophilus microplus ticks per treatment group and respective post-treatment days in field-kept cattle at the IPA experimental station.

\begin{tabular}{|c|c|c|c|c|c|c|c|c|c|c|c|}
\hline Statistic & Treatment & 0 & 7 & 14 & 21 & 28 & 35 & 42 & 49 & 56 & 63 \\
\hline \multirow[t]{13}{*}{ Average } & Abamectin & 370.75 & 30.13 & 40.25 & 29.50 & 78.88 & 78.38 & 102.75 & 188.38 & 378.38 & 71.38 \\
\hline & Ivermectin & 309.00 & 247.63 & 185.88 & 109.25 & 159.14 & 194.86 & 115.57 & 83.57 & 79.43 & 242.83 \\
\hline & Ivermectin LA & 270.63 & 211.63 & 184.88 & 203.75 & 283.29 & 183.57 & 117.71 & 79.43 & 134.33 & 155.83 \\
\hline & Amitraz & 227.40 & 172.40 & 66.60 & 67.60 & 162.75 & 90.25 & 44.50 & 45.25 & 150.25 & 86.25 \\
\hline & Amitraz + Ivermectin & 260.83 & 41.33 & 62.50 & 78.50 & 47.83 & 77.67 & 60.67 & 28.33 & 144.00 & 123.33 \\
\hline & Amitraz + Ivermectina LA & 213.25 & 46.25 & 68.75 & 51.75 & 63.75 & 49.33 & 41.33 & 31.00 & 65.00 & 101.33 \\
\hline & Amitraz + Abamectin & 153.60 & 33.00 & 38.40 & 36.60 & 138.80 & 36.00 & 64.80 & 19.25 & 213.00 & 114.00 \\
\hline & Association & 225.60 & 243.60 & 102.40 & 62.40 & 253.60 & 52.20 & 80.00 & 17.40 & 197.60 & 103.40 \\
\hline & Association + Ivermectin & 253.25 & 85.25 & 61.75 & 51.75 & 72.50 & 48.00 & 99.25 & 82.25 & 175.50 & 22.50 \\
\hline & Association + Iverm. LA & 206.50 & 60.75 & 67.00 & 106.00 & 121.25 & 85.50 & 39.75 & 41.75 & 130.50 & 65.00 \\
\hline & Association + Abam. & 282.00 & 87.60 & 104.80 & 59.60 & 288.20 & 44.80 & 93.20 & 14.25 & 225.80 & 131.20 \\
\hline & Control & 136.00 & 175.00 & 191.25 & 184.50 & 261.75 & 279.50 & 342.00 & 373.75 & 441.50 & 76.75 \\
\hline & (p-value 11) & 0.363 & $<0.001^{*}$ & $0.043^{*}$ & $<0.001^{*}$ & $0.004^{*}$ & $<0.001^{*}$ & $<0.001^{*}$ & $<0.001^{*}$ & $<0.001^{*}$ & 0.346 \\
\hline Standard & Abamectin & 175.44 & 32.27 & 43.71 & 11.65 & 141.79 & 72.47 & 99.73 & 170.01 & 168.50 & 24.41 \\
\hline \multirow[t]{11}{*}{ Deviation } & Ivermectin & 186.14 & 142.44 & 110.62 & 42.45 & 114.92 & 146.06 & 50.60 & 52.33 & 38.50 & 217.76 \\
\hline & Ivermectin LA & 149.26 & 101.88 & 134.43 & 129.20 & 153.77 & 83.09 & 47.57 & 25.61 & 121.99 & 148.90 \\
\hline & Amitraz & 144.48 & 64.24 & 60.27 & 35.41 & 83.18 & 23.67 & 24.57 & 26.59 & 90.86 & 25.20 \\
\hline & Amitraz + Ivermectin & 137.48 & 30.45 & 53.77 & 45.27 & 56.18 & 49.40 & 35.37 & 41.63 & 132.62 & 211.45 \\
\hline & Amitraz + Ivermectin LA & 99.54 & 15.02 & 45.33 & 71.70 & 65.76 & 44.29 & 36.50 & 32.14 & 9.17 & 36.12 \\
\hline & Amitraz + Abamectin & 118.14 & 13.10 & 28.98 & 41.62 & 88.70 & 25.52 & 40.12 & 10.37 & 102.88 & 84.63 \\
\hline & Association & 183.18 & 210.12 & 65.53 & 48.96 & 213.42 & 28.90 & 84.95 & 9.34 & 175.71 & 67.96 \\
\hline & Association + Ivermectin & 109.13 & 12.09 & 40.47 & 15.82 & 27.79 & 20.15 & 118.46 & 103.45 & 92.02 & 12.04 \\
\hline & Association + Iverm. LA & 92.63 & 35.42 & 81.55 & 103.04 & 137.05 & 54.18 & 30.77 & 33.29 & 59.90 & 64.50 \\
\hline & Association + Abam. & 149.13 & 68.60 & 53.64 & 31.66 & 109.34 & 32.56 & 25.38 & 14.17 & 105.24 & 78.53 \\
\hline & Control & 70.22 & 106.11 & 142.77 & 134.79 & 79.37 & 71.20 & 31.59 & 24.96 & 83.48 & 49.98 \\
\hline
\end{tabular}

( ) - - Significant difference of 5.0\%; (1)-F test (ANOVA).

Table 2. Effectiveness of acaridides applied to field-kept cattle at the IPA experimental station per post-treatment day.

\begin{tabular}{|c|c|c|c|c|c|c|c|c|}
\hline & 7 & 14 & 21 & 28 & 35 & 42 & 49 & 56 \\
\hline Abamectin & 88.78 & 79.00 & 84.01 & 69.86 & 71.96 & 69.96 & 49.60 & 14.30 \\
\hline Ivermectin & 0 & 2.81 & 40.79 & 39.20 & 30.28 & 66.21 & 77.64 & 82.01 \\
\hline Ivermectin LA & 0 & 3.33 & 0.00 & 0.00 & 34.32 & 65.58 & 78.75 & 69.57 \\
\hline Amitraz & 1.49 & 65.18 & 63.36 & 37.82 & 67.71 & 86.99 & 77.89 & 72,03 \\
\hline Association & 0 & 46.46 & 66.18 & 3.11 & 81.32 & 76.61 & 95.34 & 55.24 \\
\hline Amitraz + Iverm. & 76.38 & 67.32 & 57.45 & 81.73 & 72.21 & 82.26 & 92.42 & 67.38 \\
\hline Amitraz + Iverm LA & 73.57 & 64.05 & 71.95 & 75.65 & 82.35 & 87.92 & 91.71 & 85.28 \\
\hline Amitraz + Abam. & 81.14 & 79.92 & 80.16 & 46.97 & 87.12 & 81.05 & 94.82 & 43.71 \\
\hline Association + Iverm. & 51.29 & 67.71 & 66.53 & 72.30 & 82.83 & 70.98 & 77.99 & 60.25 \\
\hline Association + Iverm. LA & 65.29 & 64.97 & 42.55 & 53.68 & 69.41 & 88.38 & 88.83 & 70.44 \\
\hline Association + Abam. & 49.94 & 45.20 & 67.70 & 0 & 83.97 & 72.75 & 96.63 & 48.86 \\
\hline
\end{tabular}


with the chemical association organophosphorus/pyrethroid/citronel failed to produce the same good results as the other two treatments containing abamectin and required further treatment on Day +28 .

The good performance of abamectin corroborates the results of Bridi et al. [10], who, in comparing the application of abamectin with ivermectin, also demonstrated higher degrees of effectiveness with abamectin, which performed better than ivermectin, as in the present study. Comparing the action of four endectocides on Boophilus microplus infestations, Alves-Branco et al. [11] found considerable degrees of effectiveness with abamectin of $74.30 \%$ by the $35^{\text {th }}$ day, obtaining the highest rate on Day +21 . However, these authors obtained a "knock down" effect on Day 4, with a rate of $85.80 \%$, superior to the other endectocides tested. Thus, abamectin can be recommended for the control of the Boophilus microplus in naturally infected cattle during periods of intense parasitic infestation, allowing animal handlers to obtain adequate levels of protection for their animals.

Ivermectin only exhibited a certain level of effectiveness on Day $+21(40.79 \%)$, which was not sufficient for a significant reduction in the number of ticks infesting the animals and a further application of this endectocide was required on Day +28 . However, in the individual analysis of the animals from this group, a satisfactory degree of effectiveness was observed in two animals $(78.98 \%$ and $96.17 \%)$ on Day +28 . The indices found in the present study for ivermectin differ from those found by Marques et al. [12], who obtained $100 \%$ effectiveness on Day +8 . In associating ivermectin with conventional acaricides, better effectiveness of the treatments was evidenced. The data presented here may reveal the development of resistance to this endectocide in the Boophilus microplus sample. Confirmative "in vitro" tests are necessary to determine this. The resistance of this ixodidae to ivermectin has been described by Martins \& Furlong [13] and Sabatini et al. [14].

Bovines medicated with ivermectin LA also exhibited wide variation in effectiveness, requiring repetition of treatment on Day +28 , as no effective results were achieved against Boophilus microplus. The degree of effectiveness from Day +7 to Day +42 was less than $70 \%$, thereby differing from results found by Silva and Marra [15] in the state of Minas Gerais, who obtained levels above $90 \%$ on post-treatment Days 7, 14 and 21. In the city of Candiota, RS, Alves-Branco et al. [16] obtained an $86.18 \%$ degree of effectiveness on Day +4 , with a therapeutic average of $94.8 \%$ from Day +7 to Day +28 . Carvalho et al. [17], however, obtained lower tick counts from Day +14 to Day +84 using this product. When ivermectin LA was associated to acaricide baths with amitraz or the synthetic chemical association organophosphorus/pyrethroid/citronella, a greater reduction effect in infestations was obtained. It can be affirmed that this endectocide exhibits long-term effectiveness and should be used in control projects using conventional acaricide sprayings. Toma et al. [18] suggest a strategic spraying program with the application of endectocides on properties with a high degree of infestation. The authors also state that the tick control program should be adapted to each case, increasing the intervals between treatments as the parasitic load diminishes.

It is important to verify the results with the use of amitraz, as there was a significant reduction of the number of ticks on Day +7 and the treatment became more effective as the study elapsed, especially when associated with the endectocides. Post-treatment effectiveness ranged from $0 \%$ to $93.85 \%$ in the different animals. The treatment revealed that this amidine can be used if tick control is implemented adequately, thereby prolonging the effective life of this acaricide.

The association group only produced satisfactory results after a second application of the treatment on Day +28 . A reduction in infestation was observed on Day +35 , with degrees of effectiveness above $81.32 \%$. This treatment had a better performance when associated with endectocides.

\section{Conclusion}

The analysis of the results from the present study demonstrates that the use of different avermectines can assist in the development of Boophilus microplus control programs, thereby reducing the number of acaricide applications and production costs related to ticks infestations.

\section{Acknowledgements}

We are thankful to Institute of Research in Animal and Plant of Pernambuco, Brazil, for providing the study facilities to complete this research.

\section{REFERENCES}

[1] N. N. Jonsson, "Control of Cattle Ticks (Boophilus microplus) on Queensland Dairy Farms," Australian Veterinary Journal, Vol. 75, No. 11, 1997, pp. 802-807.

[2] U. Kryger, C. Deschodt and C. H. Sholtz, "Effects of Fluazuron and Ivermectin Treatment of Cattle on the Structure of Dung Beetle Communities," Agriculture Ecosystems and Environment, Vol. 105, No. 4, 2005, pp. 649-656.

[3] J. Furlong, "Control of the Tick of Bovine from Southeast Brazil,” In: T. P. Charles and J. Furlong, Eds., Doenças Parasitárias dos Bovinos de Leite, Coronel Pacheco, Embrapa, Cnpgl, 1992, 134 p.

[4] F. de P. J. Alves-Branco, I. F. Correa, M. de F. M. Sapper, et al., "Economic Impact of Health-Fluazuron in Control 
of Boophilus microplus in Beef Cattle from Rio Grande do Sul," A Hora Veterinária, Vol. 129, No. 22, 2002, pp. 19-26.

[5] R. H. Wharton and R. B. W. Utech, "The Relation between Engorgement and Dropping of Boophilus microplus (Canestrini) (Ixodidade) to the Assessment of Tick Numbers on Cattle," Australian Journal of Entomology, Vol. 9, No. 3, 1970, pp. 171-182. doi:10.1111/j.1440-6055.1970.tb00788.x

[6] N. K. Amaral, L. F. S. Monmany and L. A. F. Carvalho, "Acaricida AC 84, 63: First Trials for Control of Boophilus microplus," Journal of Economy Entomology, Vol. 67, No. 3, 1974, pp. 387-389.

[7] N. N. Jonsson, A. L. Matschoss, P. Pepper, et al., "Resistance of Holtein-Friesian Cows to Infestation by Cattle Tick (Boophilus microplus)," Veterinary Parasitology, Vol. 89, No. 4, 2000, pp. 297-305. doi:10.1016/S0304-4017(00)00213-2

[8] G. P. Oliveira and M. M. Alencar, "The Resistance of the Cattle Tick Boophilus microplus I Artificial Infestation," Pesquisa Agropecuária Brasileira, Vol. 22, No. 4, 1987, pp. 433-438.

[9] R. L. Teodoro, M. L. Martinez, M. V. G. B. Silva, et al., "Resistance to the Cattle Tick Boophilus microplus: The Brazilian Experience," Simpósio da Sociedade Brasileira de Melhoramento Animal, Pirassununga, 2004.

[10] A. A. Bridi, L. A. F. Carvalho, L. G. Cramer, et al., "Efficacy of Abamectin against the Cattle Tick Boophilus microplus Acarina, Ixodidae," Revista Brasileira de Parasitologia Veterinária, Vol. 1, No. 1, 1992, pp. 35-40.

[11] F. P. J. Alves-branco, "Efficacy of Four Endectocidas on Natural Infestation in Cattle for Boophilus microplus," A
Hora Veterinária, Vol. 111, No. 19, 1999, pp. 41-44.

[12] A. O. Marques, G. J. Arantes and C. R. Silva, "Evaluation of the Efficacy of Ivermectin to 1\% (Injectable Solution) in the Treatment of Cattle Naturally Infected for Tick Boophilus microplus (Can., 1887) (Acari: Ixodidae) and Kept in Pasture," Revista Brasileira de Parasitologia Veterinaria, Vol. 4, No. 2, 1995, pp. 117-119.

[13] J. R. Martins and J. Furlong, "Avermectin Resistance of Cattle Tick Boophilus microplus in Brazil," Veterinary Record, Vol. 149, No. 2, 2001, p. 64.

[14] G. A. Sabatini, D. H. Kemp, S. Hughes, et al., "Tests to Determine LC50 and Discrimitation Doses for Macrocyclic Lactones against the Cattle Tick, Boophilus microplus," Veterinary Parasitology, Vol. 95, No.1, 2001, pp. 53-62. doi:10.1016/S0304-4017(00)00406-4

[15] C. R. Silva and A. O. M. Marra, "Activity of the Acaricide Ranger LA (LA Ivermectin 1\%) in the Control of Boophilus microplus in Cattle Naturally Infested," A Hora Veterinária, Vol. 140, No. 24, 2004, pp. 46-48.

[16] F. P. de J. Alves-Branco, M. F. M. Sapper and J. C. B. Franco, "Evaluation of the Efficacy of a Formulation of Ivermectin to $1.13 \% \mathrm{~W} / \mathrm{V}$ Injectable Front of Natural Infestation of Cattle with Natural Boophilus microplus in Bage, Rio Grande do Sul," A Hora Veterinária, Vol. 137, No. 23, 2004, pp. 69-71.

[17] L. A. F. Carvalho, I. Bianchin, A. A. BridI, et al., "Control Antiparasitic in Beef Cattle with Long-Acting Endectocide Compared to Conventional Product," A Hora Veterinária, Vol. 106, No. 18, 1998, pp. 53-58.

[18] S. B. Toma, F. A. Marson and H. Lorenzoni, "Current Considerations on the Main Infestation of Dairy Cattle," A Hora Veterinária, Vol. 131, No. 22, 2003, pp. 21-25. 